socioeconomic indices show the south and east of England to be more affluent than the north and west, the findings in the present survey support an association between upper urinary tract stones and a high standard of living. But the finding of a higher incidence of stones in Wales than in England cannot be explained in this way. An association between living standards and stone incidence in England and Wales might partly depend on occupation, for several surveys have shown that the condition is more common among those in sedentary occupations. ${ }^{2}$ Further occupational data on patients with upper urinary tract stones in Britain arc required.

The composition of urine is greatly influenced by diet, and it has been suggested that the increase in incidence of upper urinary tract stones in Europe during this century results from changes in diet. This hypothesis is strengthened by the temporary decline in incidence observed in Norway during the war years. ${ }^{1}$ The National Food Survey has shown appreciable regional differences in diet in England and Wales. There is no obvious association between any single dietary constituent recorded in this survey and the incidence of upper urinary tract stones; but the data are relatively crude, and a more detailed study of this association is indicated. Interestingly, the regional patterns in upper urinary tract stones and ischaemic heart disease $^{5}$ are almost the reverse of each other, yet they are both disorders whose steep rise in incidence in industrialised countries has been attributed to diet.

Surveys in several countries have shown an association between the incidence of upper urinary tract stones and atmospheric temperature. The higher incidence of stones in the south of England conforms with this association, which may be due to decreased urinary output in warm climates, or the effect of increased atmospheric temperature on urinary composition. There is evidence that urinary calcium excretion is increased among men during the summer in Britain, ${ }^{6}$ and in summer urinary oxalate and urinary crystals may be increased. ' Emergency admissions for upper urinary tract colic and stones also increase during the summer months, though admissions diagnosed as stones fluctuate less than those diagnosed only as colic (figure).

We thank Mrs Barbara Gale, who helped with the analysis of the data, and Surgeon Captain N J Blacklock, who gave us helpful advice and criticism. The data were obtained through the courtesy of the Office of Population Censuses and Surveys, and the work was supported by a grant from the Department of Health and Social Security.

\author{
References \\ 1 Andersen, D A, in Proceedings of the Renal Stone Research Symposium, p 7. \\ London, Churchill, 1969. \\ 2 Blacklock, N J, in Scientific Foundations of Urology, p 235. Edinburgh, \\ Churchill Livingstone, 1976. \\ ${ }^{3}$ Rose, G A, and Westbury, E J, Urological Research, 1975, 3, 61. \\ ${ }^{4}$ Mates, J, in Proceedings of the Renal Stone Research Symposium, p 59. \\ London, Churchill, 1969. \\ 5 Morris, J N, Crawford, M D, and Heady, J A, Lancet, 1961, 1, 860. \\ 6 Robertson, W G, et al, British Medical fournal, 1974, 4, 436. \\ 7 Hallson, P C, and Rose, G A, British fournal of Urology, 1977, 49, 277.

\title{
Factor VIII-related protein on vascular intima of patients with chronic renal failure and prolonged bleeding times
}

\author{
G REMUZZI, T BERTANI， G MECCA， M B DONATI， G DE GAETANO
}

British Medical fournal, 1978, 1, 70-72

\section{Summary and conclusions}

To determine whether the prolonged bleeding time so common in chronic renal failure (CRF) was due to defective factor VIII-related activities, as in von Willebrand's disease, vascular-factor VIII-related protein was measured in patients with CRF. Factor VIII-related protein was detected by immunofluorescence on the vascular intima of all 13 patients with CRF and greatly prolonged bleeding times. This protein was also present on the vascular intima of a patient with CRF and moderate von Willebrand's disease.

These findings support a previous suggestion that the disturbed haemostasis in patients with CRF is not linked to defective factor VIII-related activities. \footnotetext{
Division of Nephrology and Dialysis, Ospedali Riuniti, Bergamo,
Italy

GIUSEPPE REMUZZI, MD, assistant in nephrology

TULLIO BERTANI, MD, assistant in nephrology

GIULIANO MECCA, MD, head of division

Istituto di Ricerche Farmacologiche "Mario Negri,"

Via Eritrea 62-20157 Milano, Italy

MARIA BENEDETTA DONATI, MD, PHD, laboratory chief

GIOVANNI DE GAETANO, MD, PHD, laboratory chief
}

\section{Introduction}

Patients with chronic renal failure (CRF) often have prolonged bleeding times. ${ }^{1}$ This abnormality has been ascribed to defective platelet function ${ }^{2-5}$ or to reduced plasma concentrations of von Willebrand factor (VIIIVWF). ${ }^{6}$ But several workers ${ }^{1}{ }^{8}$ have challenged the hypothesis that reduced VIIIVWF concentrations cause prolonged bleeding times because they have found either normal or increased VIIIVWF concentrations in patients with CRF.

Normal endothelium synthesises and releases both factor VIII-related antigen ${ }^{910}$ and VIIIVWF, ${ }^{11}$ and both contain the same single-polypeptide subunit. ${ }^{12}$ These activities are possibly functions of the same molecule and may be referred to as factor VIII-related protein.

The relation between plasma and vascular VIIIVWF in determining the haemostatic effectiveness of platelets remains obscure. ${ }^{1314}$ To complete our previous study on factor VIII concentrations in patients with uraemia, ${ }^{1}$ we therefore investigated whether the factor VIII-related protein was immunologically detectable on the vessel walls of patients with CRF and greatly disturbed primary haemostasis. The absence of such a component in the vessel wall of some patients with von Willebrand's disease has been proposed as an explanation for the prolonged bleeding time in von Willebrand's disease. ${ }^{15}$

\section{Patients and methods}

Fourteen patients (nine men and five women, aged 22-65 years) with CRF were studied just before they started undergoing haemo- 
dialysis. The CRF was caused by chronic glomerulonephritis in seven patients, polycystic kidney disease in three, chronic pyelonephritis in two, diabetic nephropathy in one, and end-stage renal disease in one.

Thirteen patients had greatly prolonged bleeding times (of over 15 minutes in 10 and of 10 to 13 minutes in three) whereas one had a normal bleeding time ( 3 minutes). Platelet counts were normal in each of these patients (range $180-320 \times 10^{9} / 1$ ). A patient with mild von Willebrand's disease who was undergoing maintenance haemodialysis ${ }^{1}$ was also studied.

Ten healthy subjects (four women and six men, aged 20-45 years) acted as controls. Their bleeding times were normal (range: 1 minute 30 seconds to 4 minutes). None of the patients or controls had received any blood transfusions for at least three months before investigation.

Bleeding time was determined in duplicate by an automatic template-like device.1 16 Plasma factor VIII-related activities (procoagulant, antigen, and ristocetin cofactor) were measured as described $^{1}$ and were found to be either normal or increased (range $80 \%$ to $400 \%$ ) except in the patient with von Willebrand's disease. ${ }^{1}$ This patient had a plasma factor VIII procoagulant activity-value of $30 \%$, factor VIII-related antigen value of $\mathbf{4 8} \%$, and a factor VIIIVWF value of $16 \%$.

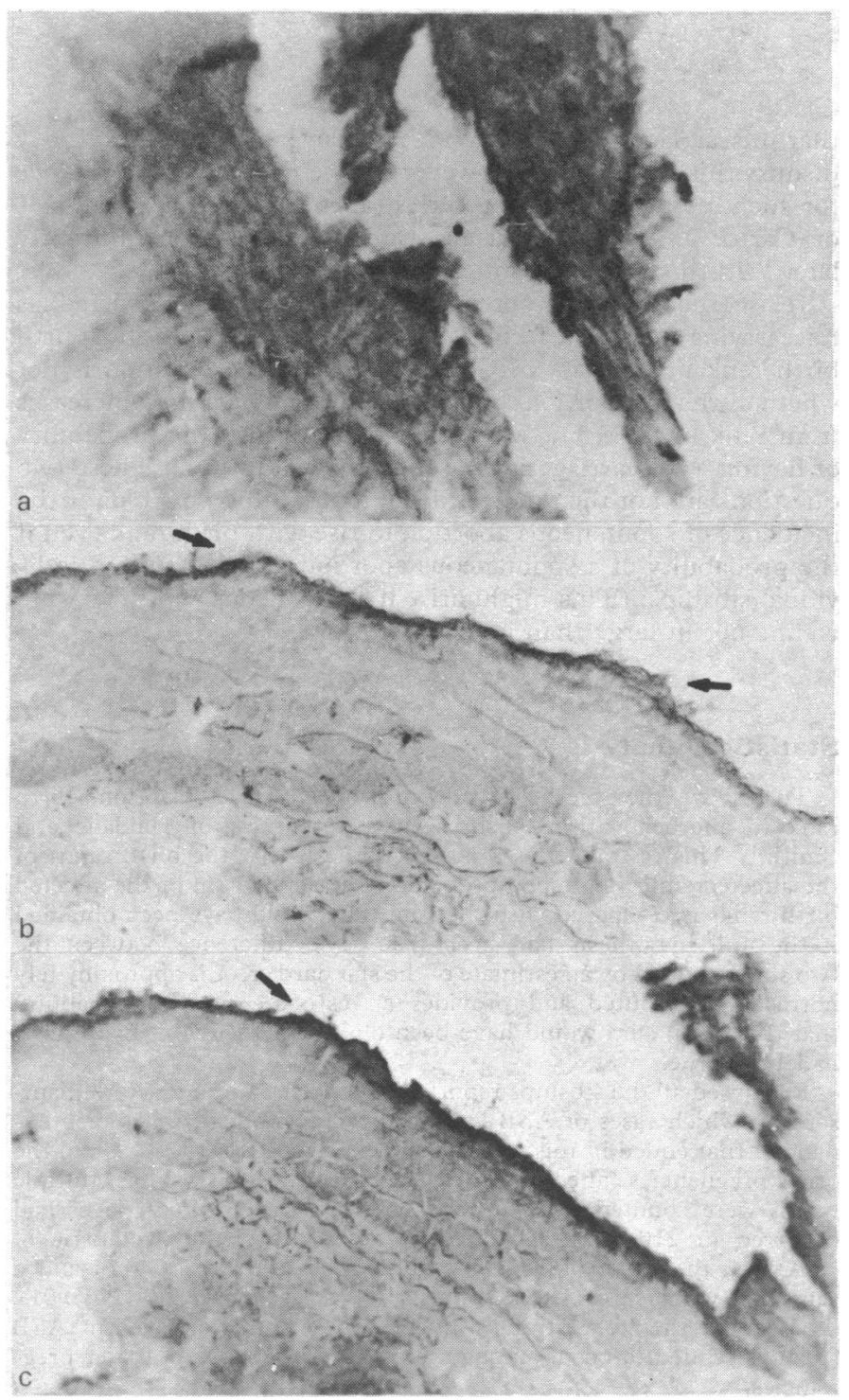

FIG 1-(a) Section of vein treated with normal non-immunised rabbit serum and fluorescein-conjugated goat anti-rabbit IgG (negative control). Note absence of specific fluorescence on surface of intima. (b) Section of vein from normal subject treated with rabbit anti-human factor VIII and fluorescein-conjugated goat anti-rabbit IgG. (c) Section of vein from uraemic patient treated as in $(b)$. Arrows indicate vascular intima showing specific immunofluorescence. This appears as thin but well-demarcated black layer lining endothelium.

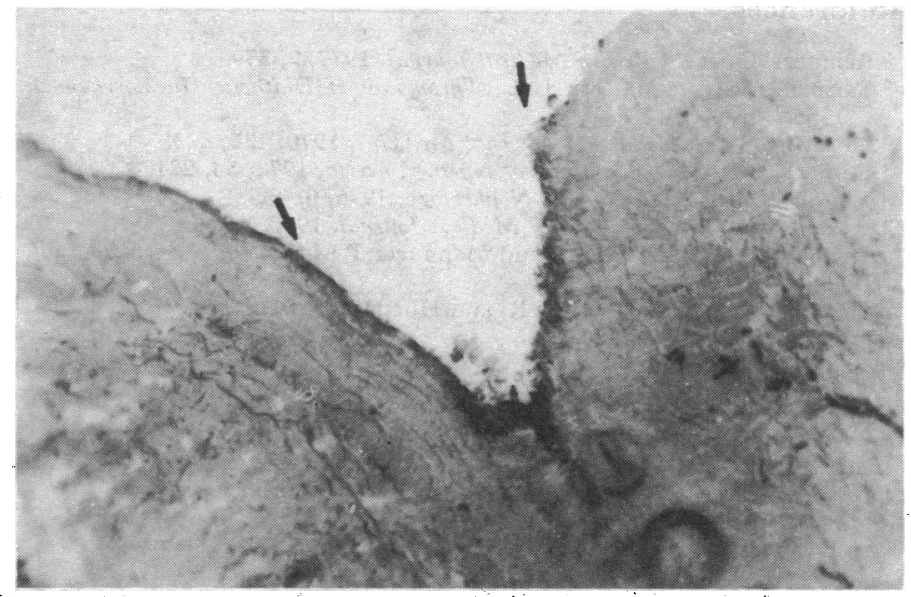

FIG 2-Section of vein from patient with CRF and moderate von Willebrand's disease treated with rabbit anti-human factor VIII and fiuoresceinconjugated goat anti-rabbit IgG. Arrows indicate vascular intima labelled with specific immunofluorescence, which appears as thin but welldemarcated black layer lining endothelium. More deeply situated fluorescence (black spots) is not specific.

Specimens of vascular tissue were surgically removed under local anaesthesia from a superficial vein of the forearm. Fresh sections were frozen and processed immediately after excision and immunohistological studies were performed as described by Bloom et al. Rabbit anti-factor VIII antiserum and fluorescein-conjugated goat anti-rabbit IgG antiserum were obtained from Behringwerke-Hoechst Italia, Milan, Italy.

Informed consent was obtained from all patients and controls.

\section{Results}

In all the sections examined the vascular intima consistently showed a thin but well-demarcated layer of fluorescence lining the endothelium. Two experienced histopathologists who read the tissue sections "blind" could not distinguish between the controls and the patients (fig 1).

Sections from the patient with CRF and moderate von Willebrand's disease also showed a layer of factor VIII-related protein on the vascular intima (fig 2).

\section{Discussion}

Our results show that factor VIII-related protein is immunologically detectable on the vascular intima of patients with CRF and greatly prolonged bleeding times. These results indicate that the haemorrhagic diathesis in these patients has a different pathogenic mechanism from that in patients with classical von Willebrand's disease and greatly prolonged bleeding times. ${ }^{13-15}$ Indeed, patients with von Willebrand's disease and prolonged bleeding times have no immunohistologically detectable vascular factor VIII. ${ }^{14}$

The finding of normal factor VIII-related material on the vascular intima of a patient with $\mathrm{CRF}$ and moderate von Willebrand's disease but a very prolonged bleeding time further supports our contention that the disturbed haemostasis in patients with CRF is not linked to defective factor VIIIrelated activities. ${ }^{1} 78$

We thank Professor A L Bloom, department of haematology, University Hospital of Wales, Cardiff, for providing us with details of the immunohistological method used in this study. E Poletti helped in collecting some vascular specimens. Annamaria Chimienti, Vincenzo de Ceglie, and Paola Seminari helped in preparing the manuscript. This investigation was supported in part by the Associazione Bergamasca per lo Studio delle Malattie Renali.

Requests for reprints should be addressed to: Dr G Remuzzi, Divisione di Nefrologia e Dialisi, Ospedali Riuniti, Bergamo, Italy 


\section{References}

${ }^{1}$ Remuzzi, G, et al, British Medical fournal, 1977, 2, 359.

2 Salzman, E W, and Neri, L L, Thrombosis et Diathesis Haemorrhagica, 1966, 15, 84.

${ }^{3}$ Horowitz, H I, Archives of Internal Medicine, 1970, 126, 823.

4 Rabiner, S F, Medical Clinics of North America, 1972, 56, 221.

5 Lindsay, R M, et al, Clinical Nephrology, 1976, 6, 335.

6 Kazatchkine, M, et al, British Medical fournal, 1976, 2, 612.

7 Ruggeri, Z M, Ponticelli, C, and Mannucci, P M, British Medical fournal, $1977,1,1085$.

${ }^{8}$ Herrmann, R P, Marshall, L R, and Hurst, P E, British Medical fournal, $1977,1,1601$.

${ }^{9}$ Bloom, A L, Giddings, J C, and Wilks, C J, Nature New Biology, 1973, 241, 217.
10 Jaffe, E A, Hoyer, L W, and Nachman, R L, fournal of Clinical Investigation, 1973, 52, 2757.

1 Jaffe, E A, Hoyer, L W, and Nachman, R L, Proceedings of the National Academy of Sciences of the United States of America, 1974, 71, 1906.

12 Jaffe, E A, and Nachman, R L, fournal of Clinical Investigation, 1975, 56, 698.

13 Caen, J P, and Sultan, Y, Lancet, 1975, 2, 1129

$14 \mathrm{Jaffe}, \mathrm{E}$ A, New England fournal of Medicine, 1977, 296, 377.

15 Holmberg, L, et al, Scandinavian Fournal of Haematology, 1974, 13, 33.

16 Praga, C, Cortellaro, M, and Pogliani, E, in Platelet Function and Thrombosis. A Review of Methods, ed P M Mannucci and S Gorini, p 149. New York, Plenum Press, 1972.

\title{
Birth ranks of spontaneous abortions in sibships of children affected by anencephaly or spina bifida
}

\author{
WILLIAM H JAMES
}

British Medical fournal, 1978, 1, 72-73

\section{Summary and conclusions}

Data on the birth rank of miscarriages within sibships in which a case of anencephaly or spina bifida (ASB) had occurred were analysed by the Haldane-Smith statistical test. This showed that miscarriages in ASB sibships tend to have a negative birth order effectthat is, they occur in earlier rather than later pregnancies within the sibship. The strongest source of bias in this analysis-the fact that mothers tend to forget early spontaneous abortions-worked against this finding, so the negative birth order effect is probably genuine.

Because ASB itself shows a negative birth order effect and because spontaneous abortions in normal sibships do not show such an effect, the additional spontaneous abortions in ASB sibships are probably of fetuses affected by ASB.

\section{Introduction}

There is a high incidence of spontaneous abortion among pregnancies in sibships in which a case of anencephaly or spina bifida (ASB) has occurred. ${ }^{1}$ - Also, relatively few pregnancies in which the fetus is affected by ASB reach full term: many more are either terminated or spontaneously aborted. ${ }^{3}{ }^{4}$ It seems natural to suppose that the additional spontaneous abortions in ASB sibships occur among fetuses that also have ASB.

This interpretation has now been questioned in one of the elaborations of the fetus-fetus interaction hypothesis. ${ }^{5-7}$ Instead it has been suggested that ASB is somehow caused by a previous spontaneous abortion. This suggestion was supported by the observation, ${ }^{7}$ now confirmed by Laurence and Roberts, ${ }^{8}$ that the pregnancy immediately before the index pregnancy, which resulted in a child with ASB, is more likely to have been reported to have miscarried than the pregnancy immediately after it. In discussing this point, Clarke et $a l^{7}$ raise the possibility

that miscarriages occur early rather than late in families. They dismiss this explanation, however: "The data gave no evidence for such a view, and in one series (anencephaly in Appendix 1 of Carter et $a l^{9}$ ) miscarriages came on average significantly later." In this paper I want to reconsider this point.

It is true that the percentage of pregnancies reported as miscarrying increased from $7^{\circ}{ }_{0}$ in the first to $20^{\circ}{ }_{0}$ in the fourth birth rank in the data of Carter et al. But the question is not whether the proportion of pregnancies miscarrying increases from rank to rank, but whether within sibships the probability of having a miscarriage increases from rank to rank. These two questions are not the same; indeed, it would be possible for the incidence of spontaneous abortion to rise with birth rank even if the probability of a spontaneous abortion declined within individual sibships. (This might arise if spontaneous abortions were commoner in large than in small sibships.)

\section{Statistical analysis}

To test whether the liability to miscarriage varies from one birth rank to another within sibships I used the test of Haldane and Smith. ${ }^{10}$ This test assumes a null hypothesis that the birth ranks of the affected siblings are equiprobable. The actual sum of the affected birth ranks is compared with the sum that would have been obtained if the null hypothesis had been true. The difference between the two sums divided by an estimate of the standard error is approximately normally distributed and provides an estimate of the probability that the actual sum would have been observed if the null hypothesis had been true.

I analysed all the sibships reported by Carter $e t a l^{9}$ and by Williamson $^{11}$ in which cases of ASB had occurred. The birth ranks of pregnancies that ended in miscarriages were tested against those of all the other pregnancies (affected and unaffected) in each sibship. Multiple births were counted as occupying one birth rank. Miscarriages had occurred in 210 sibships, and for these data the test statistic of ¿6A took the value of 4812 with an expected value of 5175 and a sampling variance of 19311 . This gave a $\mathrm{z}$ score of $2.6(\mathbf{P}<0.01)$. These data therefore strongly suggested that miscarriages in ASB sibships tended to occur among the earlier rather than the later pregnancies.

\section{Sources of bias}

Studies on birth order effects are notoriously susceptible to bias so it is worth considering some of the sources of bias.

Memory-Rates of reported spontaneous abortion may be categor- 